\title{
Research on the Behavior of College Students' Online Tourism Booking Based on TAM
}

\author{
Xiaoru Chen, Zhou Li* \\ Shenzhen Tourism College of Jinan University, Shenzhen, China \\ Email: cxr@stu2017.jnu.edu.cn, *lizhou@sz.jnu.edu.cn
}

How to cite this paper: Chen, X.R. and $\mathrm{Li}$, Z. (2020) Research on the Behavior of College Students' Online Tourism Booking Based on TAM. Journal of Service Science and Management, 13, 28-44.

https://doi.org/10.4236/jssm.2020.131003

Received: December 15, 2019

Accepted: January 18, 2020

Published: January 21, 2020

Copyright $\odot 2020$ by author(s) and Scientific Research Publishing Inc. This work is licensed under the Creative Commons Attribution International License (CC BY 4.0).

http://creativecommons.org/licenses/by/4.0/

(c) (i) Open Access

\begin{abstract}
With the rapid progress of social economy, online tourism booking has newly become a highlight for China's tourism trade and its development. College students, who have abundant disposable time, gradually build up as great tourist forces adept at using network resources. By both literature research and empirical research, this paper explores the factors affecting college students' online tourism decision-making. By establishing college students' online tourism booking behavior model based on TAM, and empirically analyzing 161 pieces of data based on SPSS22.0 and PROCESS macro plug-in, the hypotheses and modified model are verified. According to the results, perceived usefulness is still the most important factor in the college students' online tourism booking behavior model, while perceived ease of use is another essential one. Usage attitude and usage intention are combined into a common factor-"usage attitude and intention" affecting the model; Negative Internet word-of-mouth plays a moderating role in the relationship between perceived usefulness and usage attitude and intention, and perceived usefulness and perceived ease of use together act as an intermediary in the model.
\end{abstract}

\section{Keywords}

College Students, Online Tourism Booking, Technology Acceptance Model, Internet Word-of-Mouth

\section{Introduction}

As the era witnesses rapid development of tourism and Internet information technology, the Internet has imperceptibly changed the modern lifestyle and state. According to the 44th Statistical Report on the Development of Internet in China, published by China Internet Network Information Center (CNNIC), August 2019 [1], by June 2019, the number of Internet users in China had 
reached up to 854 million with the Internet penetration rate of $61.2 \%$, an increase of $1.6 \%$ compared with the end of 2018. In the past decade, the Internet penetration rate was increasing gradually and steadily. As the 2018 statistical bulletin of culture and tourism issued by the Ministry of Culture and Tourism, the number of Chinese domestic tourists, outbound tourists, domestic tourism consumption and overseas tourism consumption all ranked the top in the world in 2018 and has been in constant grow, indicating the increasing tourism demand of Chinese residents [2]. Driven by the rapid growth of tourism consumption, online tourism booking has developed rapidly. Among the Internet applications in business transactions, online tourism booking has ranked the third on usage rate, just behind online shopping and take-out, with 418 million Internet users, accounting for $48.9 \%$ of the total. In that case, more and more enterprises and users have accepted online tourism booking. Among the netizens, students account for the highest proportion, up to $26 \%$ [1].

At present, the competition among the online tourism booking platforms is becoming increasingly fierce, making how to attract potential consumers to book and consume an important topic for the tourism E-commerce platforms. Online booking is also the extension and embodiment of information technology in tourists' consumption behavior [3]. Meanwhile, with the rapid development of social economy and the improvement of people's living standards, college students, as a group with more disposal free time, have taken tourism as an important way of leisure and entertainment, while as powerful targeted users who are good at using network resources, their laws and directions when using online tourism booking are worthy of further exploration.

As such, the purpose of the current work has two aspects. Based on the Technology Acceptance Model, according to the current situation of college students in Internet use and related features of tourism products, a college students' online tourism booking behavior model is constructed to explore the influence of perceived usefulness and perceived ease of use on online travel booking behavior. Discusses the power of negative Internet word-of-mouth to introduce the public word of mouth of trustworthy objects, namely, the Internet word-of-mouth model, into the online travel booking behavior model of college students, discusses the moderating effect of Internet word-of-mouth on the online travel booking behavior model of college students, and enhances the explanatory power of the model. In general, the main focus of this paper is to study the key factors and influencing mechanisms that influence the booking behavior of college students.

\section{Literature Review}

\subsection{Online Tourism Booking Behavior}

Online tourism booking refers to that tourists, through Internet or telephone, book tourism products or services like flight tickets, hotels, holiday products, etc. from tourism service providers and pay online or offline. According to the 
current situation of online tourism trade in China, a successful transaction made by information check on the tourism service website and booked through Call Center is also regarded as an online tourism transaction. With the continuous development of web2.0, more and more consumers choose online tourism booking.

With the increasing scale of Internet users and the diversification of online tourism service business mode, the researches on online tourism booking behavior at home and abroad are also gradually emerging. Foreign scholars have a relatively early understanding of it, realizing the change of tourists' consumption behavior in the Internet age. Buhalis and Licata (2002) showed in their study on Taiwan that the online tourism transaction volume dominates the $\mathrm{B} 2 \mathrm{C}$ tourism e-commerce, making customers be accustomed to conducting independent tourism information search and self-booking of tourism products through the network [4]. Matzler et al. (2006) took online train tickets booking as an example, believing that website availability had a great impact on the booking motivation and satisfaction [5].

Among the research on online tourism booking behavior in China, Chen Haipeng et al. (2007) discussed the main reasons why consumers choose online tourism booking: time saving, comprehensive information and low price [6]. Based on consumers' features, Bao Fuyuan (2010) conducted in-depth study on the reasons and related factors contributing to the online booking, among which time saving, available information comparison and cheap price, etc. Product information, timely and effective communication with customers, and transparent tourism product cost performance are the primary factors [7]. Li et al. (2005) identified and measured the determinants of Chinese e-commerce consumers' online purchase of tourism products from seven independent sets of variables affecting Internet consumer behavior, and explored the process of online tourism consumers' transformation, from a "watcher" to a "consumer" [8]. Zhu Jingyan (2014) showed in her research on the online booking behavior of tourism website users that the implementation of the booking behavior signaling the tourism website users' transformation process from browsing to purchasing. According to the differences in online booking behavior, users are divided into four categories, and the online booking behavior characteristics of different types of tourism website users are described respectively [9].

\subsection{Technology Acceptance Model}

Technology Acceptance Model (TAM) was proposed by Davis (1989) when he used the theory of rational behavior to study users' acceptance of information system, aiming to explain and predict users' status of information system acceptance after interaction with the system over a period of time [10]. The model presents two main determinants: perceived usefulness, as "the degree to which a person believes that using a particular system would enhance his or her job performance". In contrast, perceived ease of use refers to "the degree to which a person believes that using a particular system would be free of effort" [10]. The 
framework of this model is shown in Figure 1. The model considered that behavior intention is determined by the attitude toward using and perceived usefulness, meanwhile, attitude is determined by perceived usefulness and perceived ease of use. Perceived usefulness and perceived ease of use are both affected by external variables.

Some scholars believe that consumers' online shopping behavior can refer to the technology acceptance model, since by computers, online shopping is accessible to the Internet. Consumers are required to master information technologies such as commodity search engines; consequently, those online consumers not only have the characteristics of ordinary consumers, but also of computers and network users [11]. There are two key variables: one is perceived ease of use, that is, how easy it is for an individual to use a particular information system technology; the other is perceived usefulness, referring to the degree to which individuals can improve their work efficiency with the help of new information technology.

Lin and Judy (2000) first proposed using TAM to explain consumers' acceptance of shopping websites, which showed that perceived ease of use had no significant direct effect on purchase intention, but an indirect effect on purchase intention through perceived usefulness [12]. Cheng Hua and Bao Gongmin (2003) established and tested a model of consumers' acceptance of online shopping based on TAM. Their results demonstrated that there are three key determinants affection purchase attitude and intention: consumers' perception of the usefulness, convenience and safety of online shopping [13]. Many scholars at home and abroad have verified the significance of the main paths in the technology acceptance model, such as the significantly positive impact of perceived ease of use on perceived usefulness [14] [15], the significant positive impact of perceived usefulness on attitudes and intentions [15] [16], and the significant positive impact of perceived ease of use on attitudes [17]. It is worth noting that in the study on the usage intention of smart tourism system in scenic spots by $\mathrm{Xu}$ Feifei et al., perceived ease of use significantly affected the usage intention positively [18]. Also, some scholars' research results show that the significance of some routes has not been effectively supported [15]. Therefore, the relationship between variables in the technology acceptance model may be adjusted according to different research objects and research contents. Hence, the following eight hypotheses are proposed:

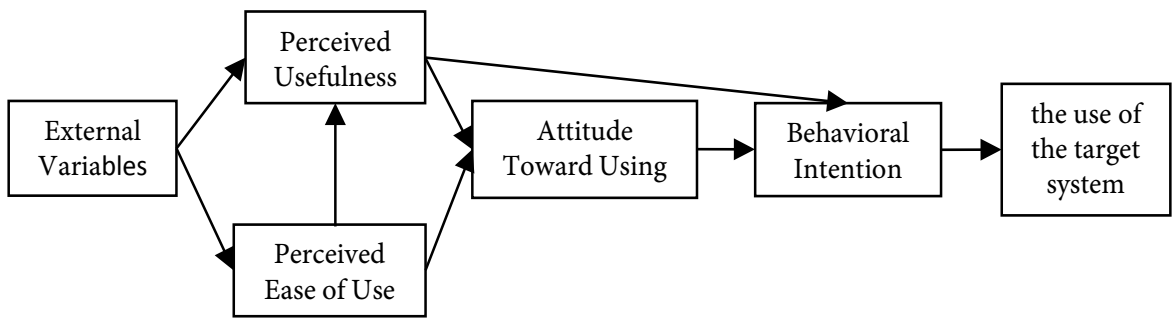

Figure 1. Technology acceptance model. 
H1. Relevant experience has a significant positive impact on perceiving usefulness.

H2. Relevant experience has a significant positive impact on perceiving ease of use.

H3. Perceived ease of use has a significant positive effect on perceived usefulness.

H4. Perceived ease of use has a significant positive effect on attitude.

H5. Perceived ease of use has a significant positive effect on usage intention.

H6. Perceived usefulness has a significant positive effect on attitude.

H7. Perceived usefulness has a significant positive effect on usage intention.

H8. Attitude has a significant positive effect on usage intention.

H9. Perceived ease of use and perceived usefulness mediates the overall model.

\subsection{Internet Word-of-Mouth}

Internet word-of-mouth refers to the behavior of consumers, through the Internet, passing on positive and negative opinions about products and services to other consumers [19]. In nearly a decade, academia and the business field have focused on and explored tourism Internet word-of-mouth. The survey conducted by Jin Zexin (2017) shows that $100 \%$ of online users tend to share through online interaction after tourism [20], and the word-of-mouth from these online reviews, serves as an important information source for consumers, as well one of the important factors influencing the consumer decision-making [21], besides, it is an important factor for booking service products and decision making [22]. Qin Qiongyu (2012) found that the perceived usefulness and ease of use from Internet word-of-mouth directly affected the development of tourism routes or the selection of tourism products, while the strength of the relationship between tourists themselves and Internet word-of-mouth disseminators directly determined further online communication [23].

As for categories of Internet word-of-mouth, positive and negative, each respectively has different effects on consumption decisions. On the one hand, consumers are more willing to share and spread negative information instead of satisfying consumption experience. On the other hand, compared with positive word-of-mouth, consumers pay more attention to negative ones, which affect their cognition, attitude and purchase intention [24]. Due to the universality and anonymity of the Internet, the influence of negative word-of-mouth is further amplified [25]. Shen Han found that the publicity effect of negative Internet word-of-mouth is significantly greater than that of positive one [22]. It can be seen that negative Internet word-of-mouth has more influence and destructive power on tourists' decision-making. Based on it, the following hypotheses are proposed:

H10. Negative Internet word-of-mouth moderates attitude and usage intention. 


\section{Methodology}

\subsection{Conceptual Model}

Based on TAM, this paper builds a model of college students' online tourism booking behavior. It is taken as the research framework helping to analyze the influencing mechanism. The model takes the technology acceptance model theory [10] as the basis and the core, combined with other factors, including the relevant experience of network using, perceived usefulness, perceived ease of use, usage attitude, intention and negative Internet word-of-mouth. This model consists of three parts: model of college students' online tourism booking behavior; influence of relevant experience from external variables on the model; influence of the moderating the variable Internet word-of-mouth on the model.

\subsection{Questionnaire Design}

\subsubsection{Questionnaire Structure}

Refer to the main variables of this study: perceived usefulness, perceived ease of use, attitude toward using, intention, relevant experience, measuring scale of Internet word-of-mouth and population characteristics, structured questionnaire is taken as measuring tool. The questionnaire consists of 5 parts, 36 items in total. Likert's scale of 5 grades is used in questionnaire in which respondents are asked to rate their opinions and attitudes towards online tourism booking according to the grades of " 5 " means "strongly agree"; " 4 " for "relatively agreement"; " 3 " for "uncertain"; " 2 " for "disagree"; "1" for "strongly disagree".

The first part is the pre-questions, which focuses on the education background and stages of the respondents, including two questions with each giving the options. The questionnaire would be stopped if the respondents are not college students.

The second part is the measurement on the Internet access and the basic information of online tourism booking (air tickets, hotels and tickets), which is mainly used to measure their experience in network use by asking 7 questions.

The third part is about the acceptance survey on the online tourism booking, a total of 20 questions.

The fourth part is about the impact of negative Internet word-of-mouth on online booking behavior, including three questions.

The fifth part is a survey on basic personal information of respondents, including gender, average monthly living expenses and the number of trips in the recent year and the city where the university is located.

\subsubsection{Questionnaire Structure}

These questionnaires have been conducted distributed and collected on an online survey platform for two weeks. A total of 163 questionnaires were distributed and all were collected, with a collection rate of $100 \%$. Among them, there are 2 invalid questionnaires and 161 valid ones, with an effective rate of $98.8 \%$. The following criteria are adopted for the judgment of invalid questionnaires: 
1) The survey would be stopped if those who reply the questionnaire are not college students;

2) The answers are same and the duration is not long enough.

According to the data collected from questionnaires, the distribution of samples is relatively average in gender and educational stages, and the respondents scattered in all regions of China. Besides, $96.3 \%$ of respondents have more than two years experience of Internet using, and $61.5 \%$ spent more than three hours on Internet each day. Among the tourism times in the past year, 59.0\% of respondents experienced one or two, and $25.47 \%$ have three or four trips. $65.21 \%$ think they have rich network experience, $91.3 \%$ search relevant tourism products information through the network before the booking, proving the respondents have a considerable ability in Internet using. They are considered as online tourism booking users or potential ones, which further illustrates the effectiveness of selected subjects. Table 1 presents a descriptive summary of the sample.

Table 1. Demographic profile of respondents $(n=161)$.

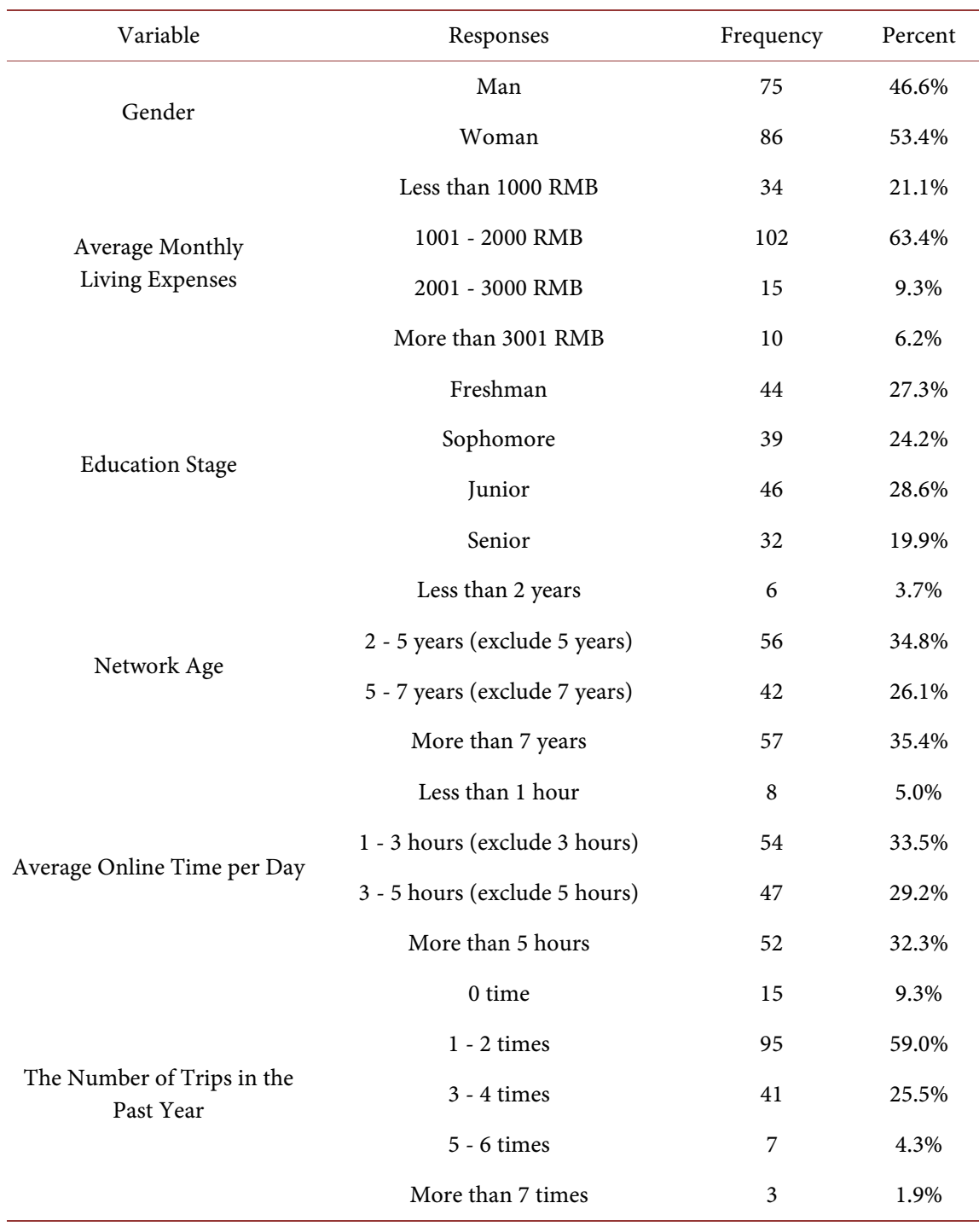




\begin{tabular}{lccc} 
Continued & & & \\
\hline & Northeast China Region & 14 & $8.7 \%$ \\
& Northern China Region & 16 & $9.9 \%$ \\
& Northwest China Region & 5 & $3.1 \%$ \\
The Area of the University & Eastern China Region & 13 & $8.1 \%$ \\
& Southern China Region & 98 & $60.9 \%$ \\
& Southwest China Region & 5 & $3.1 \%$ \\
& Central China Region & 10 & $6.2 \%$ \\
\hline
\end{tabular}

\subsection{Data Analysis}

Data support for the conclusion of this paper is provided by questionnaires which are used to collect the data of college students all over the country. The data analysis is conducted by software SPSS 22.0 which helps to carry out statistical analysis, reliability and validity analysis, factor analysis and regression analysis on effective samples, and verify the research hypothesis. The mediation effect of the model is verified by using the PROCESS V3.3 macro plug-in in SPSS. PROCESS macro plug-in, which is used to test the mediating effect of various mediation models, adjustment models and combination models based on the regression analysis was officially developed and run by Hayes in 2013.

\section{Results}

\subsection{Exploratory Factor Analyses (EFA)}

As can be seen from Table 2, the KMO statistic value of the data is 0.922 , greater than 0.90 with the significance level is 0.000 , indicating that the questionnaires have a good structural validity and are very suitable for factor analysis. By using SPSS22.0, the characteristic values of 5 factors are found to be greater than 1 through factor analysis, deviating from the original assumption.

As can be seen from Table 3, the CR value of the total scale is 0.938 , and the factors of the 26 indicators are concentrated on 5 common factors. The characteristic value of the first common factor is 12.226 with $21.966 \%$ overall variance contribution rate. The extracted 7 indicators reflect the perceived usefulness of online tourism booking of college students, which is named as "perceived usefulness (PU)" with the CR value of 0.923 . The characteristic value of the second common factor is 1.947 , the overall variance contribution rate is 19.263 , the extracted 10 indicators reflect the using attitude and intention of online tourism booking. Originally, in the hypothetical model, attitude and intentions are two interactive factors, after analysis, it is difficult to distinguish the two due to the possible small differences between the two in the whole perception. So according to the factor analysis, the two are merged into one factor, being named it "attitude and intention (A\&I)" with CR value of 0.932. Meanwhile, hypothesis 8 could not be verified. The characteristic value of the third common factor is 1.526 , and the overall variance contribution rate is $11.680 \%$. The three extracted 
Table 2. KMO and Bartlett's test $(\mathrm{N}=161)$.

\begin{tabular}{lcc}
\hline \multicolumn{2}{c}{ Kaiser-Meyer-Olkin Measure of Sampling Adequacy } & 0.922 \\
\hline Bartlett's Test of Sphericity & df & 325 \\
& Sig. & 0.000 \\
\hline
\end{tabular}

Table 3. Result of exploratory factor analyses.

\begin{tabular}{|c|c|c|c|c|c|c|}
\hline Factors \& Items & $\begin{array}{c}\text { Factor } \\
\text { Loading }\end{array}$ & Mean & SD & Eigenvalue & $\begin{array}{l}\text { Variance } \\
\text { Explained }\end{array}$ & $\begin{array}{c}\text { Cronbach's } \\
\text { Alpha }\end{array}$ \\
\hline Factor 1: PU & & & & 12.226 & $21.966 \%$ & 0.923 \\
\hline Q4 & 0.802 & 4.17 & 0.868 & & & \\
\hline Q6 & 0.772 & 4.24 & 0.810 & & & \\
\hline Q7 & 0.733 & 4.11 & 0.856 & & & \\
\hline Q5 & 0.727 & 4.17 & 0.841 & & & \\
\hline Q3 & 0.705 & 4.21 & 0.737 & & & \\
\hline Q2 & 0.703 & 4.00 & 0.873 & & & \\
\hline Q1 & 0.654 & 4.16 & 0.843 & & & \\
\hline Factor 2: A\&I & & & & 1.947 & $19.263 \%$ & 0.932 \\
\hline Q13 & 0.811 & 3.87 & 0.902 & & & \\
\hline Q20 & 0.745 & 3.86 & 0.884 & & & \\
\hline Q12 & 0.737 & 4.09 & 0.809 & & & \\
\hline Q19 & 0.669 & 4.21 & 0.762 & & & \\
\hline Q18 & 0.644 & 4.04 & 0.897 & & & \\
\hline Q14 & 0.615 & 3.99 & 0.848 & & & \\
\hline Q15 & 0.605 & 4.02 & 0.858 & & & \\
\hline Q17 & 0.600 & 4.24 & 0.884 & & & \\
\hline Q16 & 0.530 & 4.23 & 0.823 & & & \\
\hline Q11 & 0.442 & 4.11 & 0.856 & & & \\
\hline Factor 3: PEU & & & & 1.526 & $11.680 \%$ & 0.915 \\
\hline Q9 & 0.802 & 4.02 & 0.877 & & & \\
\hline Q8 & 0.770 & 3.88 & 0.911 & & & \\
\hline Q10 & 0.726 & 4.08 & 0.866 & & & \\
\hline Factor 4: NIWOM & & & & 1.462 & $9.051 \%$ & 0.781 \\
\hline Q21 & 0.814 & 4.05 & 0.879 & & & \\
\hline Q22 & 0.796 & 3.98 & 0.825 & & & \\
\hline Q23 & 0.699 & 3.99 & 0.935 & & & \\
\hline Factor 5: RE & & & & 1.027 & $8.000 \%$ & 0.720 \\
\hline Q25 & 0.810 & 3.14 & 1.528 & & & \\
\hline Q26 & 0.780 & 2.06 & 1.291 & & & \\
\hline Q24 & 0.775 & 2.39 & 1.509 & & & \\
\hline
\end{tabular}

Note. Total variation explained $69.959 \%$; total scale reliability 0.938 . 
indicators reflect the perceived ease of use of online tourism booking behavior of college students, so it is named "perceived ease of use (PEU)" with CR value of 0.915. The characteristic value of the fourth common factor is 1.462 , and the overall variance contribution rate is $9.051 \%$. Three indicators are extracted and named as "negative Internet word-of-mouth (NIWOM)" with CR value of 0.781 . The characteristic value of the fifth common factor is 1.027 , and the overall variance contribution rate is $8.000 \%$, which is named as "relevant experience (RE)" with CR value of 0.720 .

The cumulative variance contribution rate of these four factors is $69.959 \%$, indicating that the factor analysis can largely reflect the overall information, and the structural validity of this scale is acceptable. And through the factor analysis, attitude and intention are merged into a dimension, together with "perceived usefulness", "perceived ease of use", "negative Internet word-of-mouth", "relevant experience", corresponds to theoretic model mentioned above. To some extent, they verify the content validity of the scale.

\subsection{Regression Model}

To verify the effectiveness of the research model in this paper, a regression analysis is conducted on four factors: perceived usefulness, perceived ease of use, attitude and intention, relevant experience. The default data in this study is normally distributed, so model 6 of the PROCESS program is used to verify the regression path coefficient of the model composed of the above four factors, and the significance level test is also conducted to verify the validity of the hypotheses proposed above, and further modify the research model. If the path coefficient between two variables passes the significance test, it means that the path coefficient is not statistically significant to zero and the two variables are correlated, otherwise they are not significantly correlated (Table 4).

Through regression model results of Table 5 and Table 6 and 5000 times of the bootstrap analysis, in the original hypotheses, all pass significance test expect the impact of relevant experience on the perceived usefulness, namely the $\mathrm{H} 2$ fails to pass with $\mathrm{H} 1$ and $\mathrm{H} 3$ pass, $\mathrm{H} 4$ and $\mathrm{H} 5, \mathrm{H} 6$ and $\mathrm{H} 7$ pass with being merged into a general hypothesis. The higher the relevant experience value, the stronger the perceived ease of use, but it does not directly affect the perceived usefulness. Is it possible to mediate the perceived usefulness through perceived ease of use? It will be analyzed in detail by the mediating effect. The perceived ease of use will strongly affect perceived usefulness, and the improvement of both will produce an upward attitude and intention by causing influence of medium intensity, prompting respondents to generate intention, and more willing to buy related tourism products and services online.

\subsection{Moderation and Mediation Analysis}

In the PROCESS program, model 6 and model 4 are selected to verify the mediating effect of perceived ease of use and perceived usefulness. In the mediation 
Table 4. Results for regression model.

\begin{tabular}{cccccc}
\hline Regression Path & Coeff & $\mathrm{t}$ & LLCI & ULCI & Result \\
\hline RE-PEU & 0.1516 & $2.7717^{* * *}$ & 0.0436 & 0.2596 & Supported \\
RE-PU & 0.0086 & 0.2539 & -0.0585 & 0.0757 & Not Supported \\
PEU-PU & 0.6001 & $12.4780^{* * *}$ & 0.5051 & 0.6951 & Supported \\
PEU-A\&BI & 0.2180 & $3.8343^{* * *}$ & 0.1057 & 0.3303 & Supported \\
PU-A\&BI & 0.4059 & $5.4424^{* * *}$ & 0.2586 & 0.5532 & Supported \\
\hline
\end{tabular}

Note. ${ }^{* * *} \mathrm{p}<0.001 ; \mathrm{SC}=$ standardized coefficients; LLIC $=$ lower limit confidence interval; ULCI $=$ upper limit confidence interval.

Table 5. Bootstrap results for regression model parameters.

\begin{tabular}{cccccc}
\hline Regression Path & Coeff & BootSE & BootLLCI & BootULCI & Result \\
\hline RE-PEU & 0.1516 & 0.0551 & 0.0459 & 0.2648 & Supported \\
RE-PU & 0.0086 & 0.0320 & -0.0566 & 0.0684 & Not Supported \\
PEU_PU & 0.6001 & 0.0807 & 0.4349 & 0.7479 & Supported \\
PEU-A\&BI & 0.2180 & 0.0736 & 0.0693 & 0.3551 & Supported \\
PU_A\&BI & 0.4059 & 0.0980 & 0.2295 & 0.6114 & Supported \\
\hline
\end{tabular}

Note. Level of confidence for all confidence intervals in output: 95.0000; Number of bootstrap samples for percentile bootstrap confidence intervals: 5000 .

Table 6. Mediation analysis result.

\begin{tabular}{|c|c|c|c|c|c|c|}
\hline Relationships & Total Effects & Direct Effects & Indirect Effects & LLCI & ULCI & Result \\
\hline \multicolumn{7}{|l|}{ MODEL 4} \\
\hline PEU-A\&I & $1.8755^{\star * *}$ & $0.8353^{\star * *}$ & & & & \\
\hline PEU-PU-A\&I & & & 1.0402 & 0.5885 & 1.5431 & Supported \\
\hline \multicolumn{7}{|l|}{ MODEL 6} \\
\hline RE-A\&BI & $0.5248^{\star * *}$ & $0.2374^{*}$ & & & & \\
\hline RE-PEU-A\&I & & & 0.1167 & 0.0230 & 0.2506 & Supported \\
\hline RE-PU-A\&I & & & 0.0148 & -0.0965 & 0.1272 & Not supported \\
\hline RE-PEU-PU-A\&I & & & 0.1560 & 0.0377 & 0.3249 & Supported \\
\hline
\end{tabular}

Note. ${ }^{*} \mathrm{p}<0.05{ }^{* *} \mathrm{p}<0.01{ }^{* * *} \mathrm{p}<0.001$; LLIC $=$ lower limit confidence interval; ULCI = upper limit confidence interval.

model 4 , the variables included perceived usefulness, perceived ease of use, attitude and intention. The results showed that perceived ease of use plays a mediating role in perceived usefulness and attitude and intention with the total effect of 1.8755, and the direct effect and indirect effect are 1.0402 and 0.8353 with the relative effect values of $55.5 \%$ and $44.5 \%$, respectively.

Relevant experience, in model 6, is added to verify the intermediary effect of the overall model, the results show that partial mediation path, and the path from relevant experience to attitude and intention have significant effect with 
the total effect value of 0.5248 . The direct effect is significant under the confidence level of 0.05 with significant effect value of 0.2374 , the relative effect value of $45.2 \%$; In the indirect effect, the effect value of impact of perceived ease of use on attitude and intention is 0.1167 , proving that mediating path effect is significant, and the relative effect value is $22.2 \%$. The indirect effect of perceived usefulness on attitude and intention is not significant. The perceived usefulness is affected by perceived ease of use, and the effect value that affects the attitudes and intentions of the respondents is 0.1560 . The mediating effect of this path is significant with a relative effect value of $29.7 \%$. Therefore, the hypothesis H10 about the mediating effect is effectively verified.

It can be seen from Table 7 that the non-standardized coefficient of the negative Internet word-of-mouth adjustment item is -0.1432 , indicating that the adjustment variable has a negative adjustment effect on the perceived usefulness positively affecting attitude and intention. Figure 2 shows that the higher the perceived negative Internet word-of-mouth $(M+1 S D)$, the smaller the positive predictive effect produced by perceived usefulness on attitude and intention, vice versa. That is to say, with the increase of perception on Internet word-of-mouth, it is harder to improve attitude and intention by increasing perceived usefulness, so the $\mathrm{H} 9$ about regulating effect is validated (Figure 3 ).

Table 7. Moderation analysis result.

\begin{tabular}{ccccccc}
\hline & Effect & $\mathrm{se}$ & $\mathrm{t}$ & $\mathrm{p}$ & LLCI & ULCI \\
\hline PU^NIWOM & -0.1002 & 0.0408 & -2.4567 & 0.0151 & -0.1808 & -0.0196 \\
NIWOM (M - 1SD) & 0.4795 & 0.0711 & 6.7484 & 0.0000 & 0.3392 & 0.6199 \\
NIWOM (M) & 0.4059 & 0.0746 & 5.4424 & 0.0000 & 0.2586 & 0.5532 \\
NIWOM (M + 1SD) & 0.3323 & 0.0887 & 3.7449 & 0.0001 & 0.1570 & 0.5 .75 \\
\hline
\end{tabular}

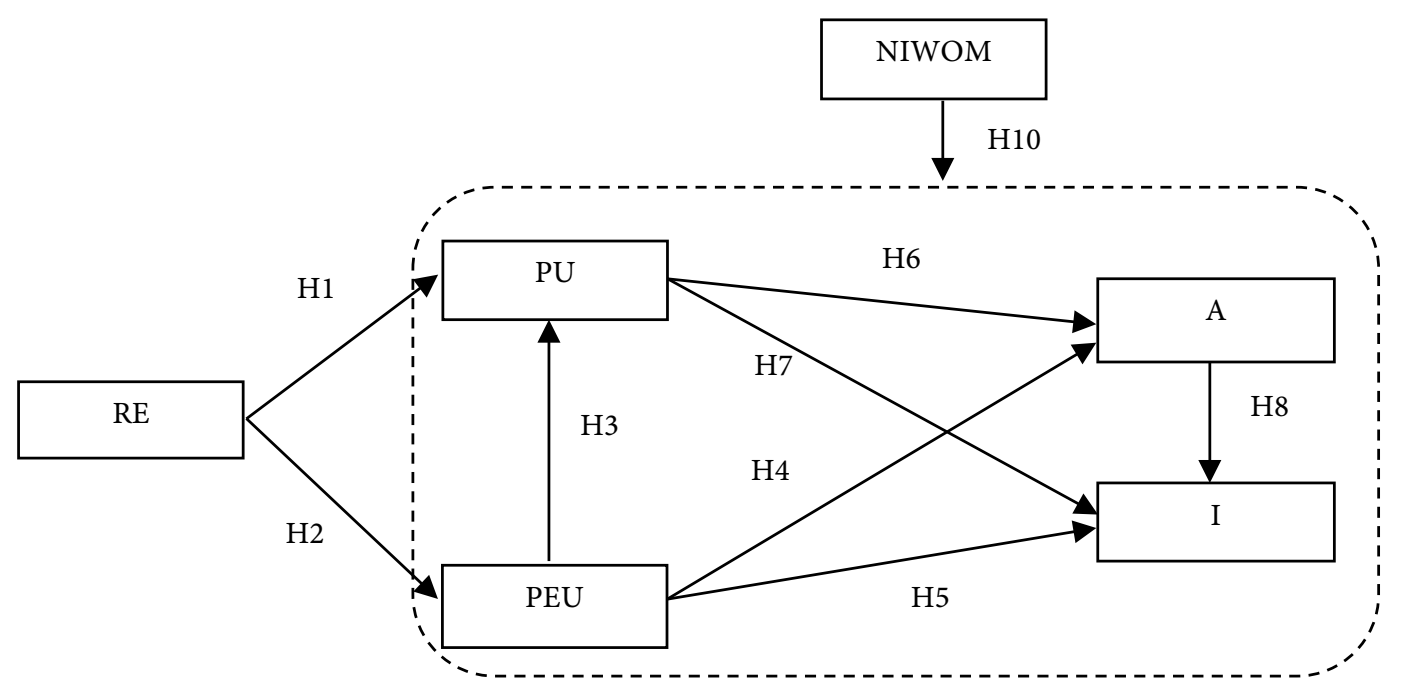

Figure 2. A model of college students' online tourism booking behavior. NIWOM = negative Internet word-of-mouth; RE = relevant experience; $\mathrm{PU}=$ perceived usefulness; $\mathrm{PEU}=$ perceived ease of use; $\mathrm{A}$ = attitude; I = usage intention. 


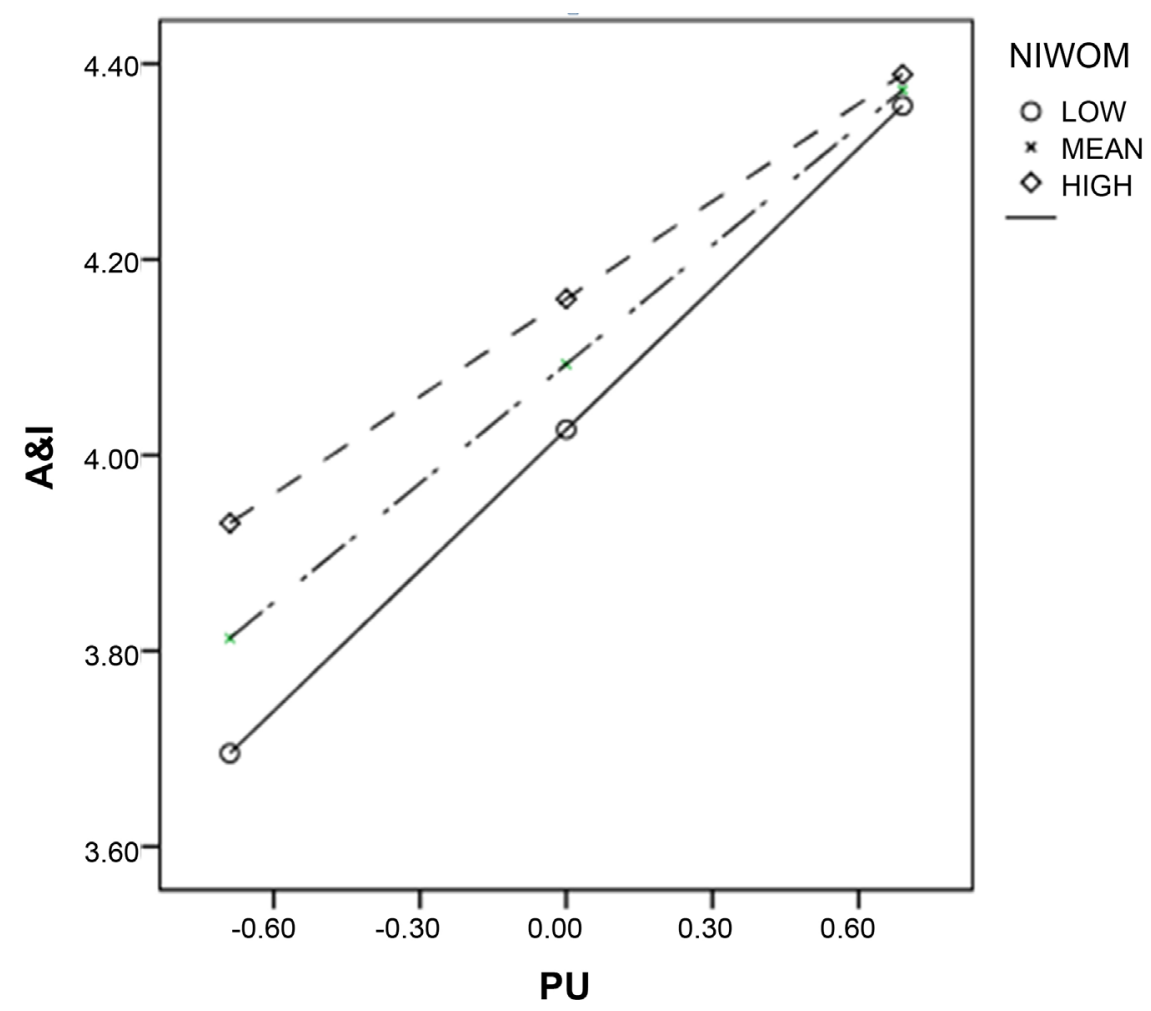

Figure 3. The moderating effect of negative Internet word-of-mouth on the relationship between perceived usefulness and attitude and intention.

\section{Conclusions}

This study attempts to explore the key influencing factors and links of college students' online travel booking behavior. By introducing negative Internet word-of-mouth and relevant external experience, combining perceived usefulness, perceived ease of use, usage attitude and usage intention, the behavior model of online travel booking for college students is constructed and modified.

Through the data analysis of the empirical study, the path coefficients among various factors in the model are discussed, and most of the hypotheses are verified. Specifically, H2 (relevant experience has a significant positive impact on perceiving ease of use), $\mathrm{H} 3$ (perceived ease of use has a significant positive effect on perceived usefulness), H9 (negative Internet word-of-mouth moderates attitude and usage intention) and H10 (perceived ease of use and perceived usefulness mediates the overall model) have been verified. Among college students, the discrimination between attitude and intention is not very high, which is easy to be confused. Therefore, the two factors in the original model are combined to extract a common factor according to the questionnaire data in the factor analysis, but it is still significantly affected by perceived usefulness and perceived ease of use. $\mathrm{H} 4$ (perceived ease of use has a significant positive effect on attitude) and H5 (perceived ease of use has a significant positive effect on usage intention), H6 (perceived usefulness has a significant positive effect on attitude) and H7 (perceived usefulness has a significant positive effect on usage intention) are com- 
bined into a general hypothesis and verified while $\mathrm{H} 1$ (relevant experience has a significant positive impact on perceiving usefulness) and $\mathrm{H} 8$ (attitude has a significant positive effect on usage intention) are not verified. According to the above test results, the adjusted research model and regression path coefficients are shown in Figure 4.

Compared with previous research results, it is found that perceived usefulness is still the key factor influencing consumers' online tourism booking behavior, while perceived ease of use is another important factor. However, for college students, attitude and intention are combined into a common factor, which together have an impact on the college students' online tourism booking behavior. Theoretically, the study on the influencing factors is conducive to further exploring college students' online tourism booking behavior. By studying the college students' online tourism booking behavior model based on TAM, it is found that $67.867 \%$ of this model is explained by perceived usefulness, perceived ease of use, attitude and intention toward using, relevant experience Internet word-of-mouth. Consistent with previous studies, perceived usefulness is still the most important intermediary factor, which is significantly related to the attitude and intention, which perceived ease of use is another important factor affecting attitude and intention.

There is a significant positive impact between relevant experience and perceived ease of use. That is, the more relevant experience college students have, the easier for them to identify the authenticity and effectiveness of information, so as to understand its practicality and operation, the more they perceive the ease of online tourism booking. And the intermediary effect of perceived usefulness and perceived ease of use perception impact the attitude and intention of online booking. Negative Internet word-of-mouth has a negative moderating effect on the relationship between perceived usefulness and attitude and intention. This is because of the rapid development of network information, the credibility of network information is becoming lower and lower, and the authenticity of many positive word-of-mouth needs to be studied, while that of negative one is relatively large. Therefore, college students pay more attention to negative one and whether they will buy online products or services is affected by it.

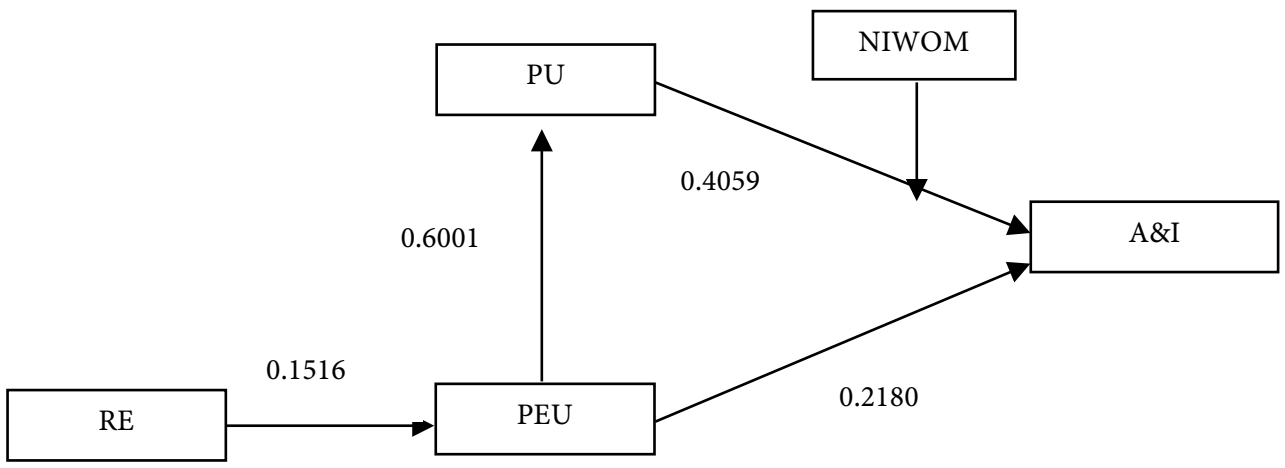

Figure 4. Modified model of college students' online tourism booking behavior. 


\section{Implications}

This study provides favorable theoretical support for the tourism e-commerce platform that offers customized tourism products for college students. Because of the perceived usefulness is still a key factor affecting college students' online tourism booking behavior, so tourism enterprises should take the demands of college students as the center, from the perspective of their perceived usefulness design reasonable online booking products and services so as to improve repeated purchase rate, develop more potential users and promote the stable and healthy development of online tourism. Furthermore, college students are active and willing to share their own feelings online. Compared with the positive Internet word-of-mouth, the negative one plays a significant negative regulatory role to the attitude and intention, so online tourism booking platform needs to pay more attention to the public opinion monitoring. More importantly, it needs to solve the problem at its source by providing real, cost-effective products and services, and fluent booking process, effective and timely feedback and after-sale mechanism, meanwhile, control technology and service level at each key node of online booking, making respondents enjoy the thoughtful service, and buy the products they prefer, as well completing high-quality online booking and offline experience and reducing the negative online word-of-mouth at the source to improve its online booking intention.

\section{Limitations and Future Research}

This study is not free of limitations. Firstly, the sampling size in this study is insufficient due to comprehensive reasons. $60 \%$ of the 161 questionnaires are collected from Southern China, mainly scattering in Guangzhou and Shenzhen, so the data analysis and empirical research conclusions are not representative enough. Moreover, research objects can be further subdivided to carry out empirical research on college students in first, second and third-tier cities, so as to provide more targeted research results and data support for tourism enterprises and online tourism booking platforms.

Secondly, the influencing factors account for the model need to be further explored from other perspectives for they are diversified. This paper only introduces the negative Internet word-of-mouth as a moderating variable and relevant experience as an external variable to conduct relevant research and make new findings. From the perceived risk or other angles, the influence of perceived risk or other factors on the online tourism booking behavior could be further studied, and research model of college students' online booking behavior could be further explored too, with the purpose of conducting a more comprehensive analysis on the impact mechanism, embracing better understandings to the motivation of college students choosing online booking.

\section{Conflicts of Interest}

The authors declare no conflicts of interest regarding the publication of this paper. 


\section{References}

[1] China Internet Network Information Center (2019) The 44th China Statistical Report on Internet Development.

http://www.cac.gov.cn/2019-08/30/c_1124938750.htm

[2] Ministry of Culture and Tourism of China (2019) 2018 Statistical Bulletin on Cultural and Tourism Development. http://zwgk.mct.gov.cn/auto255/201905/t20190530_844003.html?keywords

[3] Zhang, J.C. (2019) Is E-Booking a Planned Behavior? A Study on the Effects of Tourist's Habits and the Two-Stage Moderating Effects of Risk Perception. Tourism and Hospitality Prospects, 3, 43-64. https://doi.org/10.4018/IJTHMDA.2019070102

[4] Buhalis, D. and Licata, M.C. (2002) The Future E-Tourism Intermediaries. Tourism Management, 23, 207-220. https://doi.org/10.1016/S0261-5177(01)00085-1

[5] Matzier, K., Waiguny, M., Toschkov, A. and Mooradian, T.A. (2006) Usability, Emotions and Customer Satisfaction in Online Travel Booking. In: Hitz, M., Sigala, M. and Murphy, J., Eds., Information and Communication Technologies in Tourism 2006, Springer, Vienna, 135-146. https://doi.org/10.1007/3-211-32710-X_21

[6] Chen, H.P. and Mu, H.L. (2007) Study on Online Travel Booking Market and B to C e-Commerce Model. Scientific and Technological Information, 7, 88-89.

[7] Bao, F.Y. (2010) Analysis of Consumer Behavior in Online Travel Booking. Journal of Zhejiang Tourism Vocational College, 2.

[8] Li, L. and Wang, J. (2005) From “Onlooker" to "Buyer"-Predicting Online Tourism Purchasing Intentions in China. Tourism Tribune, 5, 49-56.

[9] Zhu, J.Y. (2014) The Analysis of Online Booking Behavior of Travel Websites' User. Master's Dissertation, East China Normal University, Shanghai.

[10] Davis Fred, D. (1989) Perceived Usefulness, Perceived Ease of Use, and User Acceptance of Information Technology. MIS Quarterly, 13, 319-340. https://doi.org/10.2307/249008

[11] An, S.F. and Wan, J.P. (2007) TAM Based Online Shopping Motivation Integrated Model. Journal of Information, 5, 52-55.

[12] Judy Chuan-Chuan, L. and Hsipeng, L. (2000) Towards an Understanding of the Behavioral Intention to Use a Website. International Journal of Information Management, 20, 197-208. https://doi.org/10.1016/S0268-4012(00)00005-0

[13] Cheng, H. and Bao, G.M. (2003) Empirical Study on Determinants of Online Shopping Intention. Quantitative Economy Technical and Economic Research, 11, 150-153.

[14] Huang, Y., Backman, S.J., Backman, K.F. and Moore, D.W. (2013) Exploring User Acceptance of 3D Virtual Worlds in Travel and Tourism Marketing. Tourism Management, 36, 490-501. https://doi.org/10.1016/j.tourman.2012.09.009

[15] Guo, Y.Z. and Li, X.M. (2018) An Empirical Study on Consumers' Intention of Buying Tourism Products with Mobile Payments-An Integration Model of TAM and TPB. Journal of Sichuan University (Philosophy and Social Science Edition), 6, 159-170.

[16] Wallace, L.G. and Sheetz, S.D. (2014) The Adoption of Software Measures: A Technology Acceptance Model (TAM) Perspective. Information \& Management, 51, 249-259. https://doi.org/10.1016/j.im.2013.12.003

[17] Ariff, M.S.M., Yeow, S.M., Zakuan, N., Jusoh, A. and Zaidi Bahari, A. (2012) The Defects of Computer Self-Efficacy and Technology Acceptance Model on Behavioral Intention in Internet Banking System. Procedia-Social and Behavior Sciences, 57, 448-452. https://doi.org/10.1016/j.sbspro.2012.09.1210 
[18] Xu, F.F. and Huang, L. (2000) Tourists' Willingness to Use Smart Tourist Attractions System: An Integrated Model Based on TAM and TTF. Tourism Tribune, 33, 108-117.

[19] Bussiere, D.E. (2015) Evidence and Implications of Electronic Word-of-Mouth. Proceedings of the 2000 Academy of Marketing Science (AMS) Annual Conference. Developments in Marketing Science, 5, 361. https://doi.org/10.1007/978-3-319-11885-7_89

[20] Jin, Z.X. (2017) Data Analysis of Online Travel Users in the Context of "Internet Plus". Market Modernization, 19, 54-55.

[21] Chevalier, J. and Mayzlin, D. (2006) The Effect of Word of Mouth on Sales: Online Book Reviews. Journal of Marketing Research, 43, 345-354. https://doi.org/10.1509/jmkr.43.3.345

[22] Shen, H., Zhao, J. and Hu, F.L. (2019) The Influence of E-Word-of-Mouth on Online Purchase Decision. Tourism Forum, 1-11. http://kns.cnki.net/kcms/detail/45.1363.K.20191107.1559.002.html

[23] Tan, Q.Y. (2012) Research on the Internet Word-of-Mouth's Influence on Nanning College Students' Tourism Decision-Making. Master's Dissertation, Guangxi University, Nanning.

[24] Shao, Y.M., Liu, M.R. and Kong, J.J. (2015) Research on the Influence of Online Word-of-Mouth Direction and Source Credibility on Consumers' Purchase Intention. Business Economy Study, 25, 70-72.

[25] Ward, J.C. and Ostrom, A.L. (2006) Complaining to the Masses: The Role of Protest Framing in Customer Created Complaint Web Sites. Journal of Consumer Research, 33, 220-230. https://doi.org/10.1086/506303 